\title{
PERFECTING THE MANAGEMENT OF OPERATIONS AT THE MANAGERIAL DEPARTMENT OF A UNIVERSITY HOSPITAL
}

\author{
P. Slavova* \\ Department of Industrial Business, University of National and World Economy, Sofia, Bulgaria
}

\begin{abstract}
Currently, the share of healthcare services offered in Bulgaria is comparatively smaller than that in the European Union member states, however, the Bulgarian healthcare sector continues to be on the route towards the establishment of the new healthcare system. The leading activities in the sector are the provision of comprehensive healthcare services - improvement of health and disease prevention, outpatient medical assistance, hospital medical assistance (treatment, surgery and post-surgery services).

The provision of well-structured and correctly organised business processes, as well as their management are basic economic problems with increasing significance for the management of the healthcare sector.

The review of numerous literature sources, useful practices and statistical data shows that there are gaps in the methods pertaining to the issues related to the methods of perfecting the management of business processes within medical institutions.

The main objective of this paper is:

To present the current state of the management of processes crucial for the healthcare institution and also to prove the usefulness of software tools for perfecting business processes in order to improve their management. Based on this, proposals may be made in order to improve the management of business processes within the healthcare institution.

The subject of this paper is the Urology Clinic as part of the management structure of a University Hospital. The data are analysed both in summary and in groups to which comparative analysis is applied.

Together with the analysis performed on the study results, comparative analysis is also applied to the results provided prior to the introduction of the Balanced Scorecard (BSc) ${ }^{1}$ by the healthcare institution. The comparative analysis is used to find relationships which characterise the applicability of adapted methodology for perfecting the management of business processes through the Balanced Scorecard for the efficiency within the healthcare institution.
\end{abstract}

Key words: management, business processes, efficiency indicators, healthcare services.

JEL: D21: D22; I15; L21

\section{INTRODUCTION}

In the modern dynamic and rapidly-developing market, business organisations, including healthcare institutions, as part of a business system, are faced with numerous difficulties and challenges. These stem from increasing competition (1) due to globalisation of the economic environment, as well as the significant negative impact on companies, in

*Correspondence to: PETYA SLAVOVA,

Department of Industrial business, University of

National and World Economy, Sofia 1700,

Bulgaria, " $8^{\text {th }}$ December" str., e-mail: p_fin@abv.bg

412 particular, healthcare institutions and their operations as the result of the past financial and economic crisis.

The modern challenge that business organisations face is the need to increase their efficiency, which requires the application of innovative methods and tools to support this.

\footnotetext{
${ }^{1}$ The Balanced Scorecard system or BSc is a popular modern method for efficiency management. It is based on the study of numerous existing best practices and was developed at Harvard in the early 90 s of the 20th century.
} 


\section{Background}

Based on an analysis of the current situation in the Urology Clinic at a University Hospital, this paper presents the topical priorities and intentions of the author with regard to the management of the clinic, also describing the methodology, methods and approaches needed to detail and implement these priorities and intentions so as to ensure the stability, sustainability and continued development of the organisation.

The basic characteristics of the organisation, the internal and external environment, the applicable regulations and the current state of the Clinic are given. The main problems and challenges for its operations are determined.

The paper presents the views of the author about the need to update the strategic objectives and priorities of the Clinic. It also collects and summarises the main intentions for change and development during the current three-year period (2017-2019).

The paper presents the management methods applied in order to adopt and implement the new development strategy of the Clinic.

The expected results from the management of the Clinic during the chosen period are summarised.

The precise analysis of the current status, the identification of challenges, the selection of up-to-date priorities and the application of modern and globally recognised management methods are achieved through:

$\checkmark \quad$ Cutting the costs by optimising the allocation of resources and avoiding errors and redundancies;

$\checkmark \quad$ Improved satisfaction of the patients as the effect of focusing the entire organisation towards their needs and expectations;

$\checkmark \quad$ Increased security for the patient through early identification and overcoming of defects and weaknesses in work processes;

All this shows the importance of the study for the perfection of operations at the Clinic which in turn leads to a positive financial result.

\section{Description and analysis of the current situation}

The research and analysis indicate that following the adoption of the Health Insurance Act, the public relations in the healthcare sector changed dramatically. New principles have been introduced related to the financing of the system, the distribution and allocation of cash flows within it.

The Urology Clinic is a University Hospital unit, whose mission is closely connected with this hospital and is responsible for the following public goals:

- Diagnosis and treatment of patients with excretory and reproductive system of males, eligible for subsequent in-hospital treatment or diagnostic interventions, performed only in hospital settings, as well as urological consulting assistance for all hospital units.

- Adoption and implementation of modern diagnostic and therapeutic methods in accordance with international standards.

- Professional development and maintaining high qualifications of medical staff.

- Methodical and consultancy assistance for doctors - urologists from all over the country.

- $\quad$ Teaching Urology at all levels within the graduate, post-graduate and continued medical qualification settings, preparing teaching aids.

- $\quad$ Scientific research and applied science activities.

The description of the structure of this type of healthcare institution is specified in Figure 1.

All fields and sectors are headed by people who are also treating physicians. There are 103 employees working at various positions in the clinic, which according to the Small and Medium Enterprises Act makes it a mediumsized organisation.

The following main activities are performed at the Clinic:

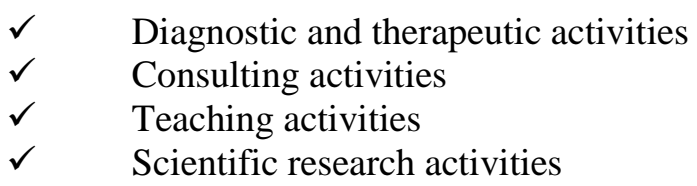

These main activities are inextricably linked with the financial results and an integral part of the proper management of the entire structure.

\section{Strategic objectives and priorities}

This exposition presents the author's views related to the current strategic objectives and priorities for the activities of the Clinic and is described as the approach for their formulation, therefore detailing the long-term and short-term objectives and tasks. 


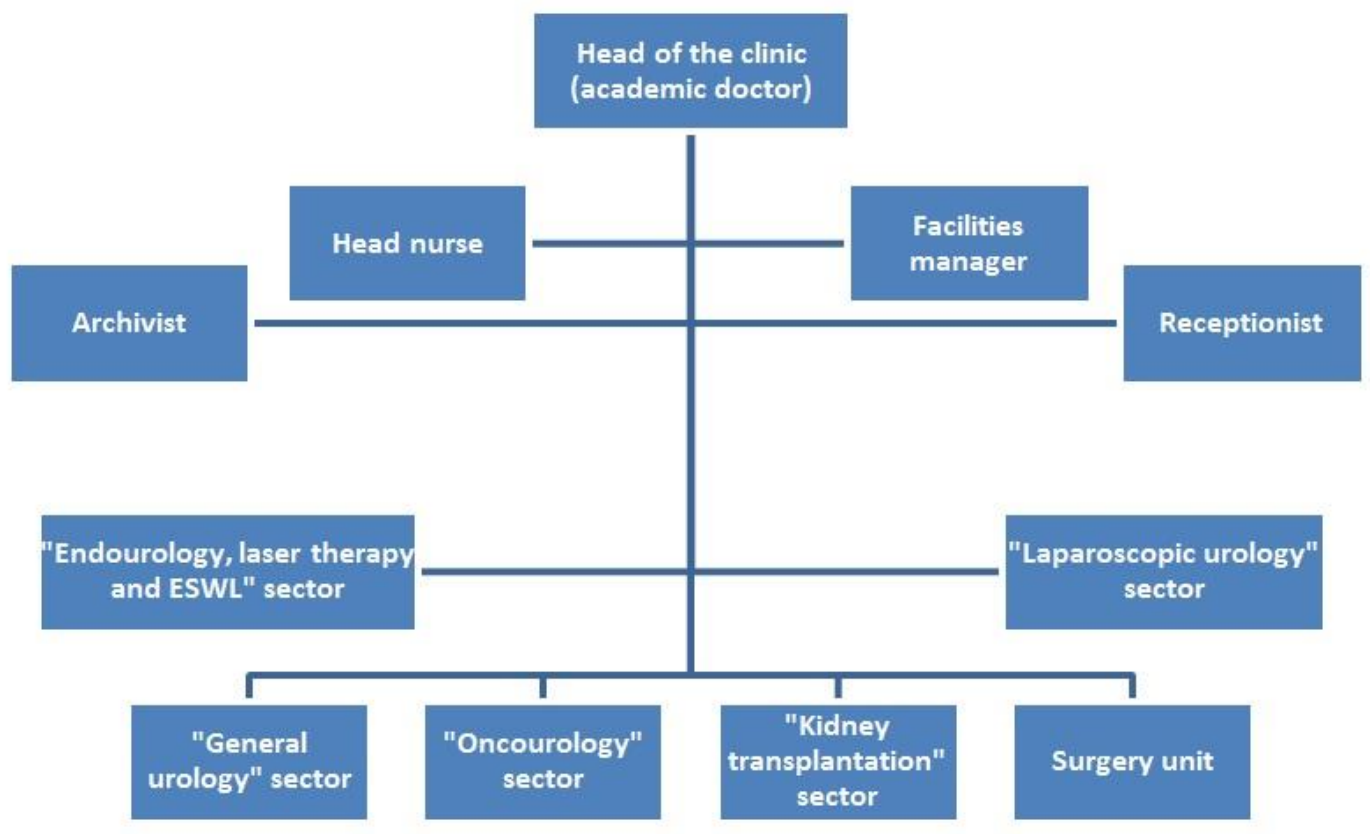

Figure 1. Organisational structure of the Urology Clinic of a University Hospital

\section{Clinic.}

The SWOT analysis is a key tool used as part of the strategic planning process within the organisation. It consists of an assessment of the internal and external environment and identification of the strengths and weaknesses (internal), as well as the opportunities and threats (external).
The results of the SWOT analysis provide useful input for the synchronisation of resources and capabilities of the organisation with the competitive environment within which it operates. In this regard, the methodology plays a crucial role for the selection and formulation of the organisation's strategy.

\begin{tabular}{|c|c|}
\hline STRENGTHS & WEAKNESSES \\
\hline $\begin{array}{l}\text { High level of professionalism of the medical staff; } \\
\text { Command of the latest methods for diagnosis of } \\
\text { urological disease; } \\
\text { urological disease; } \\
\text { u High satisfaction of patients with the quality and } \\
\text { efficiency of the healthcare provided at the clinic; } \\
\text { all professional levels. }\end{array}$ & $\begin{array}{l}\text { Need to perfect monitoring, control and assessment of } \\
\text { healthcare activities at the clinic; } \\
\text { h Insufficient remuneration compared to the level of } \\
\text { healthcare services provided; } \\
>\text { Inadequate building facilities; } \\
\text { Insufficient and outdated equipment for modem high- } \\
\text { tech methods of treatment; } \\
\text { Constantly declining motivation of the staff at the } \\
\text { Clinic due to the low remuneration for their labour and bad } \\
\text { conditions at work; } \\
>\text { Weak motivation for improvement of qualification and } \\
\text { acquiring a bachelor's degree by healthcare professionals; } \\
>\text { Unfavourable ratio of highly qualified medical } \\
\text { specialists and healthcare professionals; } \\
>\text { Slow bureaucratic procedures for admission of patients. }\end{array}$ \\
\hline OPPORTUNITIES & THREATS \\
\hline $\begin{array}{l}\text { Providing financing for repairs and finishing } \\
\text { construction works on existing clinic premises and } \\
\text { modernisation of the patient bed facilities in connection with } \\
\text { the forthcoming restructuring of healthcare in the Republic } \\
\text { of Bulgaria; } \\
\text { Increasing self-funding in accordance with the existing } \\
\text { regulations; } \\
\text { new Development, implementation and standardisation of } \\
\text { Medical University and the Scientific Research Fund at the } \\
\text { Ministry of Education and Science; } \\
\text { forticipation of the scientific teaching staff in projects } \\
\text { for perfecting the available infrastructure and improvement } \\
\text { of qualifications. }\end{array}$ & $\begin{array}{l}\text { The under-financing of activities by various clinical } \\
\text { paths within the existing calculations of the National Health } \\
\text { Insurance Fund; } \\
\text { finsecurity with regard to the possibility of attracting } \\
\text { financial resources due to the inefficiency of existing } \\
\text { regulations; } \\
\text { Limited public resources for financing medical services; } \\
\text { Increasing competition from existing and newly } \\
\text { established treatment organisations; }\end{array}$ \\
\hline
\end{tabular}

Figure 2. SWOT analysis of the Urology Clinic 
Based on the strengths and weaknesses, opportunities and threats found, the strategic objectives and priorities of the activities at the clinic have been updated for the current threeyear period.

The Urology Clinic has the following strategic objectives:

I. Diagnostic process - to provide free choice, accessible, reliable, adequate, sufficient in scope and quality timely diagnostics and treatment according to the actual needs of the public and the modern standards of medical science and practice.

II. Administrative and commercial activity - effective financial, economic and administrative policy adequate for the needs and interests of the clinic on one hand, and the healthcare needs and interests of the hospital on the other.

III. Teaching and scientific research activities - maintaining the established status as a leading university clinic and a core facility for teaching students, specialists and doctors, as well as striving to achieve and maintain a high level of professionalism corresponding to the norms and standards applicable in the European Union.

- $\quad$ Long-term objectives

In order to achieve and affirm the strategic objectives, the clinic has set long-term goals, namely:

I. Preparation and implementation of a longterm investment policy with the following goals:

1. Increased capabilities related to the diagnostic and treatment process through investment in the purchase of modern equipment and technology

2. Improvement of the qualify of life for patients by creating more pleasant living conditions within the clinic

3. Increased management efficiency through the setup of a modern information system at the clinic, compatible with that of the hospital

II. Optimising the diagnostic, treatment and managerial processes within the clinic in order to modernise it in accordance with European standards and regulations.

III. Participation of the clinic in the unified diagnostic complex, which is part of the general hospital facility in order to meet public needs in the field of medical practice and science in the field of Urology.
Based on a survey of the current managerial practice in healthcare organisations (mostly hospitals and clinics), a combination of methods has been selected, which has proven popular and applicable in healthcare management.

The strategic management and the efficiency of operations management at the Clinic are performed with the aid of a Balanced Scorecard. The methodology is very suitable for the detailing of the strategic priorities of the organisation, their conversion into operating concepts and the continuous objective and balanced measurement of deviations and achievements; for the allocation of responsibilities among staff at all organisational levels; for the measurement of the contribution of each employee and the internal and external communication at the clinic as a whole.

The management of operations shall be assisted by the introduction of Business Process Management - BPM. The development of detailed descriptions of all operations as processes is the basis for achieving transparency and standardisation of the practices at the Clinic; finding and correcting weaknesses; supporting staff training; facilitating the introduction of new practices. This allows the measurement of the efficiency of processes and its comparison to that of other similar organisations (benchmarking). Also, quality can be monitored and staff is incentivised to continuously optimize and perfect operations.

The combination of strategic management systems and business process management is a modern and globally-accepted model of organisational management (2-5). It helps ensure a sustainable synergy between strategy, organisational structure, business processes and information systems, achieving overall increase of managerial competence at the Clinic up to modern levels.

\section{- Strategic management and efficiency management}

In recent years, the healthcare sector in Bulgaria has been undergoing continuous reform. Healthcare facilities are expected to become more flexible and to come as close as possible to the achievements of their counterparts in the most developed nations in the world. Bulgarian hospitals and clinics face several main issues: 
$\checkmark \quad$ Modernisation;

$\checkmark \quad$ Developing and strengthening their administrative and managerial capacity;

$\checkmark \quad$ Improving the quality of healthcare services;

$\checkmark \quad$ Increasing satisfaction and trust of patients;

$\checkmark \quad$ Improving transparency and reporting of activities.

The competent strategic management of healthcare organisations allows them to successfully systematise the priorities and to perform the activities for their implementation. During the analysis of the current state of the Urology Clinic, several management areas have been identified where a positive impact can be achieved by introducing suitable methods, practices and software tools in order to:

- Facilitate the collection and summarising of information on financial and natural efficiency scores for the operations of the organisation at all levels;

- $\quad$ Facilitate the analysis of statistical data and management decisions-making focused on expected results;

- $\quad$ Prioritise the initiatives, projects and programmes according to their compliance with the regulations, mission, vision and strategy of the organisation;

- Ensure constant and continuous monitoring, optimisation and focusing of strategic priorities and objectives of the clinic in accordance with the overall strategic framework for development of the Bulgarian healthcare sector;

- Support the activities of programoriented budgeting;

- $\quad$ Popularise the strategy, priorities, set objectives and initiatives undertaken among as many of the staff as possible;

- Increase the motivation of staff by evaluating the contribution of different departments and even of individual employees for the achievement of the set objectives;

- Create a common electronic knowledge fund (regulatory documents, internal instructions, guidelines, descriptions, best practices) accessible for every employee during their everyday work;

- $\quad$ Support the training process for staff in an intuitive and accessible manner with direct access from every workstation to the latest information and suitable supporting aids;
- $\quad$ Establish a communication medium for quick and effective feedback, sharing of comments, ideas and best practices between employees both vertically and horizontally;

- Facilitate the summarising, systematising and extraction the necessary information for the preparation of accounts, references and reports for internal use and submission to higher hospital and administrative bodies;

- Increase transparency and accountability for clinic operations before stakeholders, organisations and the public.

The organisational and managerial framework, which would correspond most efficiently to the identified needs for organisational changes and optimisation, if implemented, is the Balanced Scorecard.

The Balanced Scorecard (or BSc) is the most popular modern method for measuring and managing the efficiency of operations within business organisations. The work of a large group of scientists and consultants in recent years has shown that the method can be applied just as successfully for the strategic management of organisations in the public and NGO sectors. Their administrative and managerial capacity are directly linked to the quality of services for people and the public, and the proper use of expenditures, therefore its improvement is the main objective of the management teams of the respective organisations (6). There are various practices for adapting the Balanced Scorecard system for non-commercial operations, and with the most popular among these, the system includes a set of indicators that describe the activities of the organisation in four main aspects, similar to those in the private sector:
- $\quad$ Services for patients;
- Internal processes;
- $\quad$ Training and development;
- $\quad$ Financial resources and results.

The Balanced Scorecard system is a key management tool for the achievement of the mission, vision and main priorities of the organisation and in the healthcare sector. It is focused on the performance of the organisation's strategy through monitoring a mutually balanced set of financial and nonfinancial, lagging and leading indicators, internal and external factors of influence (Figure 3). 


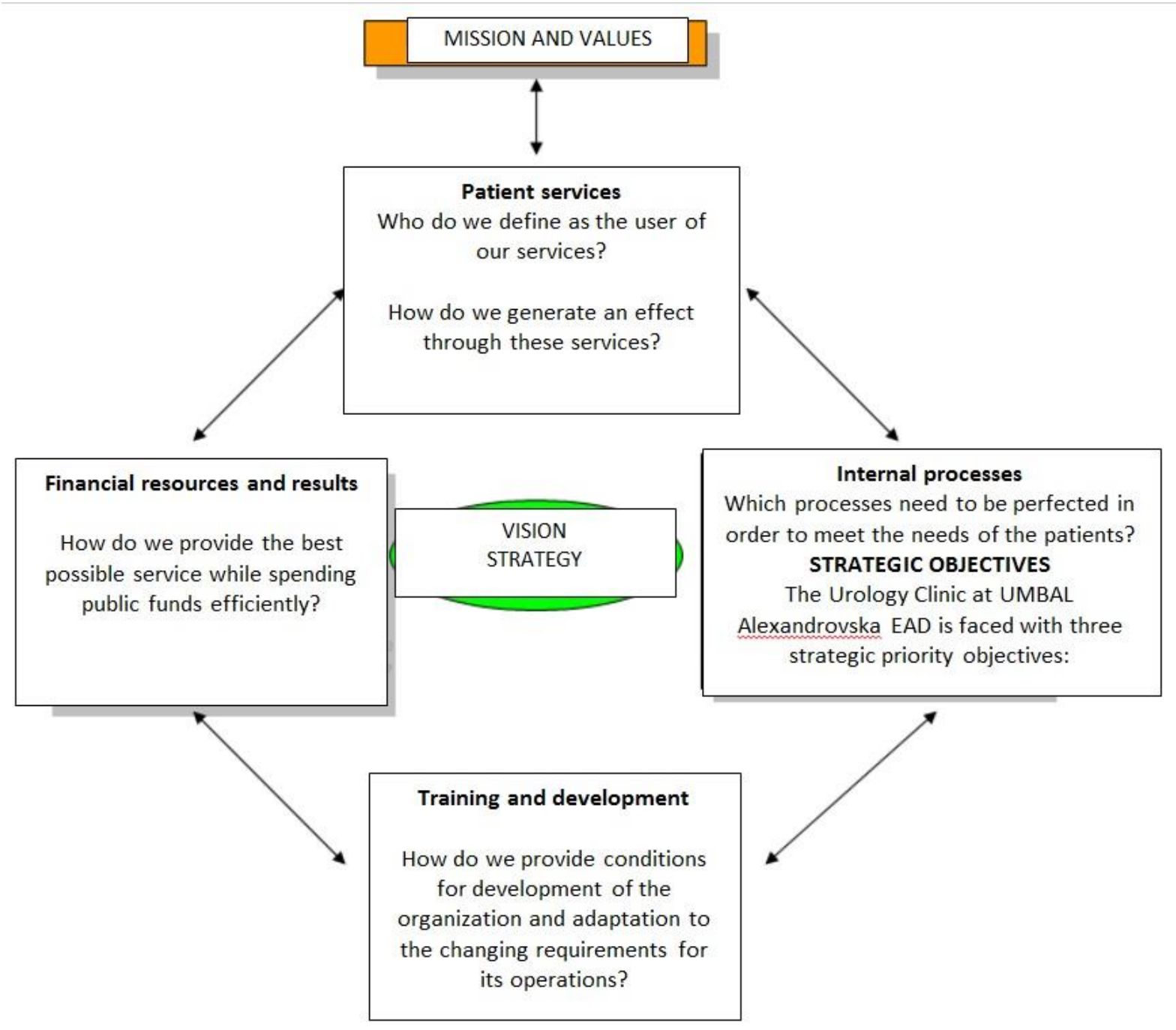

Figure 3. The four perspectives of the Balanced Scorecard for the Urology Clinic

\section{- Missions:}

Strategic management of the organisation

The Balanced Scorecard, through the continuous provision of up-to-date and complete information about the efficiency of the organisation, allows the management team of the clinic to use this as the main tool for strategic management of operations.

The scorecard system is based on the coordinated concept for the mission, vision and strategy of the organisation and the transformation of this notion into a set of priorities, efficiency indicators, target values and suitable initiatives for each of the four perspectives. The expression of the vision and strategy through clear and easily measurable indicators supports the Clinic in determining the specifics of the general and impractical statements of the mission and values of organisations in the healthcare sector. As a result of the effort put into developing the system, the employees can focus on their daily tasks to achieve clear objectives. The use of the method as a means of translating the strategy into working concepts creates a new environment which is easy to navigate and can be used by all staff members in the performance of the set tasks.

The successful implementation of the strategy requires awareness and its application at all organisational levels. The Balanced Scorecard may be developed hierarchically (cascaded) vertically in a manner which would allow all employees to demonstrate their daily contribution to the achievement of the common objectives. Each department and team has its specific responsibilities, which should be expressed through individual scorecards closely related to the organisational priorities at the highest level.

The organisational link between the various categories of staff will be visualised by establishing a hierarchical structure of the scorecard. The heads of units and their 
subordinates will get the opportunity to be assessed according to their actual contribution to the achievement of the clinic's pre-set coordinated common objectives and priorities. The development of a Balanced Scorecard is useful in terms of establishing a connection between the strategies and the allocation of resources within the Clinic. During the development and subsequent application of the system, priorities, indicators and target values for each perspective are not simply selected but also specific initiatives and plans of action are noted for each indicator, which would enable the achievement of its target values. The monitoring of activities and the performance of the initiatives is much easier when these are integrated into common priorities and strategy.

The human and financial resources needed to achieve the objectives form the core of the scorecard system for the organisation. The evaluation of the necessary resources for the functioning of the clinic is clearer and better justified when linked to its strategic priorities. The management team of the clinic is expected to assess the start or delay of each project and initiative in the light of the general framework developed around the organisation's mission. The introduction of the scorecard system has led to a reassessment and prioritisation of all current operations of the various organisational levels according to their relevance and significance for the main priorities. As a recommendation, the allocation of resources shall not be based on the intuition and experience of the managers but on the efficiency of the active business processes. The management decisions made this way represent a well-justified position in the process of preparation and coordination of the program-oriented budget of the clinic.

The Balanced Scorecard translates the vision and strategy of the organisation into a suitable set of indicators in four mutually balanced perspectives. This expands significantly the horizon of the management team, which can now analyse more than the usual purely financial information. The combination of the scorecard values reflects the level of performance of the strategy by the Clinic and makes it possible to assess whether the current results bring it closer to the achievement of the coordinated priorities.

The strategy should be viewed as a collection of hypotheses and expectations for the way to achieve the success of the organisation. In order to make real sense, the Balanced Scorecard indicators need to be integrated in a manner, which demonstrates these hypotheses and assumed cause and effect relationships. The management team of the organisation should take into consideration that the investment in staff training would return in the form of improved quality of healthcare services. It is possible that in time, the set objective related to the training is achieved but the quality of services remains unchanged. Such an effect would mean that the assumption is wrong and the efforts should be focused in another direction, for example, to provide all staff access to the largest possible volume of information resources related to their daily work.

The analysis of the assumed cause and effect relationships and the dependencies between individual indicators over time is a labourintensive and extensive task but even only starting such a review and continuous optimisation of the strategy and reassessment of the initiatives represents a significant step forward towards strengthening the management capacity of the clinic.

\section{Business Process Management.}

\section{The processes are important because:}

- These are a core component of the organisation;

- The organisation, which is focused on the processes, may analyse these in order to find the reasons for any type of problem (related to the structure, employees, control or the processes themselves);

- Most organisational issues are the basis of a specific process;

- The organisations manage their activities more effectively and efficiently when the manner of thinking is process-oriented.

From the point-of-view of the patients, a healthcare unit exists only to create "value" for them - to ensure their good health. However, at many healthcare institutions, the actual creation of "value" for the patient is not the responsibility of any specific employee. In these healthcare institutions, the medical staff, support staff and managers concentrate on each of the steps which lead to improved quality of medical services for the patient but no-one focuses on all steps as a whole. One employee takes the call of the patient or greets them at the reception desk, another collects the necessary information, a third one decides 
what treatment to prescribe, a fourth one performs laboratory tests but in fact nobody oversees all that. These organisations suffer a process crisis.

In normal "non-process" organisations, employees know little outside the highlyspecialised framework of their individual job descriptions. Managers do not consider it necessary to educate their employees about anything outside the specific skills needed for the performance of individual tasks. This isolation may be complemented by the fact that organisations control strictly the flow of information and share it only if necessary. In order to unlock its potential, each party interested in its performance should understand it as a whole and should be aware how their individual efforts contribute towards this performance. Medical staff needs sufficient information about their patients, competitors and the priorities of the Clinic in order to make decisions, which fall within their responsibilities.

Every employee of a process-oriented healthcare institution should be able to answer the following questions: What process are you yourself part of? Can you describe it in twentyfive or fewer words? What is its objective? How does your process create "value" for the patient? How do other people, who work with you also contribute "value"? What do people who work directly before and after you within the process do? What efficiency indicator does the organisation assess in the performance of your process? What is the current level of this indicator? How do you know when you are doing well personally? What other processes intersect with yours? What need do these processes have for yours and what does your process need from these? What actions are you taking to improve your process? People who can answer these questions have successfully adopted process-oriented thinking.

\section{Strategy map.}

The Balanced Scorecard, initially devised as a means to perfect the measurements of intangible assets within organisations, is transformed into a powerful tool to describe and implement the strategy. The model, describing the organisational strategy for creating "value" in four perspectives, in fact provides the language in which top management can discuss the directions and priorities of their organisation (7). They can consider the strategic aspects not as achievement indicators in four mutually independent perspectives but as series of cause and effect relationships between the strategic objectives within the system. The overall interaction between these relationships can be represented in a form which today is called a strategy map. The map - visualisation of the cause and effect relationships between components of the organisational strategy represents the same significant and crucial tool as the balanced scorecard system itself.

The general strategy map of the Urology Clinic is derived from the simple model of the Balanced Scorecard which includes strategic objectives in four perspectives. The strategy map adds new details which illustrate the dynamics of strategic development over time. These also introduce a modular aspect which improves clarity and focus. Regardless of the methods used to formulate the strategy of the organisation, the strategy map provides a unified and consistent way of describing this strategy so that the objectives and indicators are not only found but also measured and managed. The strategy map represents the missing link between the formulation of the strategy and its implementation.

\section{CONCLUSION}

The concept of operations and resource management at the Urology Clinic is based on two main methodologies: 1) efficiency management and strategic management through a Balanced Scorecard; and 2) Active Business Processes Management.

When collecting and summarising the information about the mission, history and legal framework for the clinic, as well as the development of an initial SWOT analysis, strategic objectives and the strategy map, the problematic fields are identified and sectorspecific guidelines for improvement are provided. The main objective of the study is achieved using modern software tools which contribute to the analytical aspect of the developed concept. The main problems formulated by the author are solved, namely identifying the relationships characterising the applicability of the adapted methodology for perfecting business process management through a Balanced Scorecard at the Urology Clinic.

\section{REFERENCES}

1. Milusheva, V. Prioritetnost na resheniyata pri organizatsionno proektirane za povishavane na konkurentosposobnostta, 
"MOBILNOST ZA EDIN SVARZAN SVYAT", Izdatelski kompleks - UNSS, S. 2017

2. Robart Kaplan, Deyvid Nortan, Balansirana sistema ot pokazateli za efektivnost: Kak da prevarnem strategiyata $\mathrm{v}$ deystvie, Klasika $\mathrm{i}$ Stil, 2005

3. Robart Kaplan, Deyvid Nortan, Strategicheski karti: Da prevarnem nematerialnite aktivi v osezaemi rezultati, Klasika i Stil, 2006

4. Oliveira, J. 2001. "The Balanced Scorecard: An Integrative Approach to Performance Evaluation." Healthcare Financial Management 55 (5): 42-46.

5. Webe, D. O. 2001. "A Better Gauge of Corporate Performance." Health Forum Journal 44 (3): 20-24

6. „Viziya za razvitie na zdravnata strategiya i reforma v Balgariya", First open forum „Zdravnata strategiya i zdravnoosiguritelniyat model v Balgariya", April 2006
7. Paul R. Niven, Balanced Scorecard Stepby-Step for Government and Nonprofit Organizations, Wiley, 2003.

\section{Other references}

Gladilov, Delcheva, „Ikonomika na zdraveopazvaneto", 1998

Curtright, J. W., S. Stolp-Smith, and E. Edell. 2000. "Strategic Performance Management: Development of a Performance Measurement System at the Mayo Clinic." Journal of Healthcare Management 45 (1): 58-68.

Meliones, J. N., et al. 2001. "No mission [not equal to] No Margin: It's that Simple." Journal of Healthcare Finance 27 (3): 21-29.

Pink, G. H., et al. 2001. "Creating a Balanced Scorecard for a Hospital System." Journal of Healthcare Finance 27 (3): 1-20.

Naredbi na Ministerstvoto na zdraveopazvaneto

https://www.mh.government.bg/bg/normativni -aktove/naredbi/ 